\title{
GLOBAL SENSITIVITY ANALYSIS METHODS APPLIED TO HYDROLOGIC MODELING WITH THE SAC-SMA MODEL
}

\author{
Eduardo M. Uliana ${ }^{*}$, Demetrius D. da Silva², Michel C. Moreira ${ }^{3}$, Donizete dos R. Pereira ${ }^{2}$ \\ ${ }^{1 *}$ Corresponding author. Universidade Federal de Mato Grosso/ Sinop - MT, Brasil. E-mail: morganuliana@gmail.com \\ ORCID ID: https://orcid.org/0000-0003-2107-4634
}

\section{KEYWORDS}

rain-flow model, Sobol method, Morris method.

\begin{abstract}
This study aimed to use global sensitivity analysis (GSA) methods to evaluate the sensitivity of the SAC-SMA hydrologic model parameters in the estimation of daily flows of the Piracicaba river basin. The study was carried out in three sections of flow monitoring of the Piracicaba river basin, with an area of $5,304.0 \mathrm{~km}^{2}$ and located in the State of Minas Gerais, Brazil. For the global sensitivity analysis of the SAC-SMA model, the Morris and Sobol methods were used. The model parameters showing high sensitivity were UZFWM, which represents the free water depth in the upper zone of the soil and interferes with the subsurface flow and groundwater aquifer recharge; ADIMP, which represents the additional impermeable area of the basin and interferes with the direct runoff generation; and LZPK, LZSK, LZFPM, and LZFSM, which are related to the base flow of the basin. The results showed that most of the SAC-SMA model parameters do not provide expressive variations in the output variable, most of the SAC-SMA model parameters with high sensitivity are the intervenient in the base flow, and the Morris method should be used as a preliminary analysis to the use of the Sobol method.
\end{abstract}

\section{INTRODUCTION}

Hydrologic simulation models allow understanding the hydrologic behavior of a basin, making possible their use for the evaluation of strategies of water resources management and prediction of extreme events (Andrade et al., 2013).

Several hydrologic models have been developed and used worldwide with a variety of purposes (Devia et al., 2015). Among these models, Soil Moisture Accounting (SAC-SMA) (Burnash, 1995), developed in the United States for flood forecasting on the Sacramento River (California), stands out.

Even considering the importance of hydrologic modeling, the great difficulty of its practical application is the calibration/validation and understanding of the behavior of hydrological models with a high number of parameters. In this context, the sensitivity analysis is an important tool to be adopted before the calibration/validation process and flow estimation (Shin et al., 2013; Song et al., 2015).

Sensitivity analysis allows evaluating the influence of input data and their interactions on the performance of mathematical models. The results of this analysis allow understanding the behavior of hydrologic models and are useful in the parameterization, optimization, and quantification of model uncertainties (Song et al., 2015).

From the evaluation of the interaction between parameters and identification of those with a significant influence on the output results of the model, the sensitivity analysis allows reducing the number of parameters incorporated in the calibration and time required for its execution (Rakovec et al., 2014). This reduction is obtained by setting values for parameters with no significant influence on the output results of the model (Herman et al., 2013).

Sensitivity analysis methods can be divided into local and global. Local methods determine the importance of the parameter in a single point of the sample space and should be applied only to linear or additive models (Tian, 2013).

On the other hand, global sensitivity analysis (GSA) methods evaluate the interaction between the input data and quantify the influence of parameters on the variable response of the model considering all its range of variation. Therefore, they can be applied to nonlinear and non-monotonic models, such as hydrologic models (Tian, 2013). Among the GSA methods, Morris (Morris, 1991) and Sobol (Sobol, 1993) stand out.

\footnotetext{
${ }^{2}$ Universidade Federal de Viçosa/ Viçosa - MG, Brasil.

${ }^{3}$ Universidade Federal do Oeste da Bahia/ Barreiras - BA, Brasil.

Received in: 9-4-2017

Accepted in: 12-18-2018
} 
The Morris method requires little computational effort, being simple to implement and easy to interpret. In addition, it has presented itself as a promising tool for the qualitative evaluation of the sensitivity of hydrologic model parameters and as a preliminary analysis to the use of variance-based GSA methods, which are computationally more costly (Herman et al., 2013; Cariboni et al., 2007).

In order to verify the convergence and validation of GSA methods, Sarrazin et al. (2016) applied the Morris method to identify sensitive parameters of the hydrologic models SWAT, HyMod, and HBV. Moreau et al. (2013) used the method to identify the input information and the most sensitive parameters of the distributed TNT2 agrohydrological model. Studies by Song et al. (2013) and Zhan et al. (2013) corroborated the success of using the Morris method to identify sensitive parameters of hydrologic models.

The Sobol method is another adequate GSA method for sensitivity analysis of nonlinear models with a large number of parameters, being more robust than the Morris method, allowing quantifying individually the effects of parameters and their interactions on the output data of the model (Yang, 2011; Zhang et al., 2013).

Studies such as those of Zhang et al. (2013) and Van Werkhoven et al. (2009) used the Sobol method to analyze the sensitivity of SWAT and SAC-SMA hydrologic model parameters, respectively.
Thus, this study aimed to evaluate, through global sensitivity analysis and using the Morris and Sobol methods, the sensitivity of the SAC-SMA model parameters applied to the Piracicaba river basin for estimating daily flows.

\section{MATERIAL AND METHODS}

\section{Study area and database}

In order to perform the sensitivity analysis of the SACSMA model, also known as Sacramento, daily data of pluviometric, fluviometric, and meteorological stations located in the Piracicaba river basin, located in the centraleastern portion of the State of Minas Gerais, and in its surroundings (Table 1 and Figure 1).

For the application of SAC-SMA, the drainage areas upstream of the three fluviometric stations located in the Piracicaba river basin were used as sub-basins (Figure 1).

Daily flow data were used for the periods from September 1, 1990 to December 31, 1992, July 1, 2002, to December 31, 2006, and September 1, 1990, to December 31, 1993, recorded in the fluviometric stations Carrapato (56640000), Rio Piracicaba (56610000), and Mário de Carvalho (56696000), respectively (Table 1). These periods were selected because they did not present faults in the hydrometeorological data of the stations listed in Table 1.

The drainage areas of the fluviometric stations 56640000 , 56610000, and 56696000 are equal to 427.5 , $1,164.2$, and $5,304.0 \mathrm{~km}^{2}$, respectively.

TABLE 1. Information on the stations used in the study.

\begin{tabular}{cccccc}
\hline Code & Name & Station & Latitude $\left(^{\circ}\right)$ & Longitude $\left(^{\circ}\right)$ & Altitude $(\mathrm{m})$ \\
\hline 01942029 & Mário de Carvalho & $\mathrm{P}$ & -19.525 & -42.644 & 232 \\
01943008 & Santa Maria do Itabira & $\mathrm{P}$ & -19.442 & -43.118 & 538 \\
01943027 & Usina Peti & $\mathrm{P}$ & -19.881 & -43.367 & 1,110 \\
02042031 & Fazenda Cach. D'Antas & $\mathrm{P}$ & -20.011 & -42.674 & 280 \\
02043059 & Colégio Caraça & $\mathrm{P}$ & -20.097 & -43.488 & 1,300 \\
02043056 & Fazenda Água Limpa & $\mathrm{P}$ & -20.305 & -43.616 & 965 \\
01943007 & Santa Bárbara & $\mathrm{P}$ & -19.945 & -43.401 & 748 \\
01943001 & Rio Piracicaba & $\mathrm{P}$ & -19.923 & -43.178 & 623 \\
56640000 & Carrapato & $\mathrm{F}$ & -19.972 & -43.459 & 755 \\
56610000 & Rio Piracicaba & $\mathrm{F}$ & -19.932 & -43.173 & 748 \\
56696000 & Mário de Carvalho & $\mathrm{F}$ & -19.524 & -42.640 & -42.866 \\
2042024 & Viçosa & $\mathrm{M}$ & -20.766 & & 712 \\
\hline
\end{tabular}

P: pluviometric station; F: fluviometric station; M: meteorological station. 

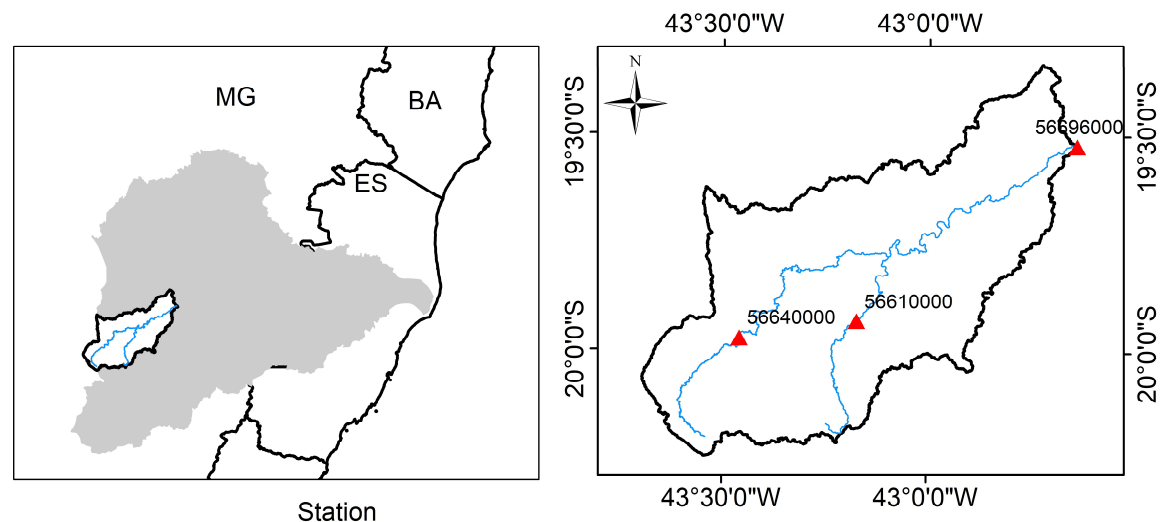

\section{Legenda}

$\Delta$ Fluviometric station

Hydrography

Piracicaba river basin

Doce river basin

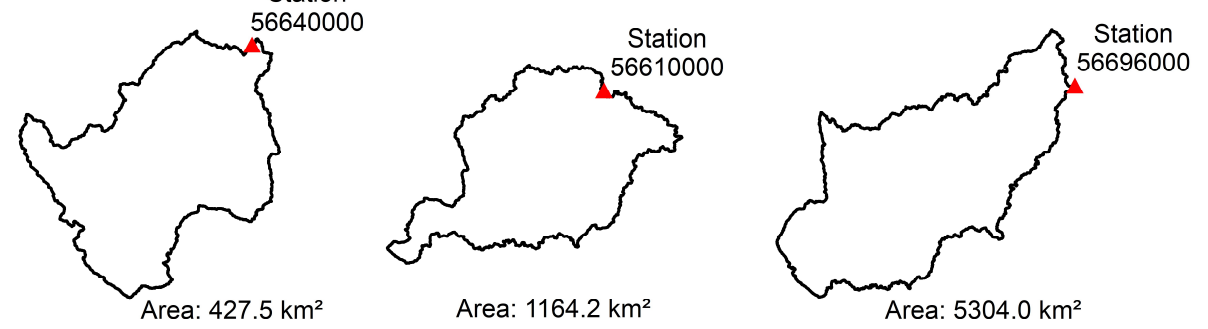

FIGURE 1. Piracicaba river basin, highlighting the three sub-basins used in the study.

\section{Hydrologic modeling with SAC-SMA}

The SAC-SMA model requires as input variables precipitation and reference evapotranspiration data. Daily reference evapotranspiration $\left(\mathrm{ET}_{0}\right)$ was calculated by means of the method of Hargreaves and Samani (Hargreaves \& Samani, 1985). The average precipitation in the drainage area of each sub-basin was obtained by the Thiessen method, as described by Macêdo et al. (2013).

The SAC-SMA model performs water balance in the upper and lower areas of the soil in order to quantify the direct, surface, subsurface, primary basis, and supplementary basis flows, which contribute to the flow of watercourse.

Figure 2 shows the schematic representation of the SAC-SMA model, which has 13 parameters that characterize the hydrologic system, whose values must be obtained by means of automatic or manual calibration.

Detailed descriptions of the SAC-SMA model, according to hydrologic concepts, can be obtained in Burnash (1995) and Andrews et al. (2011).

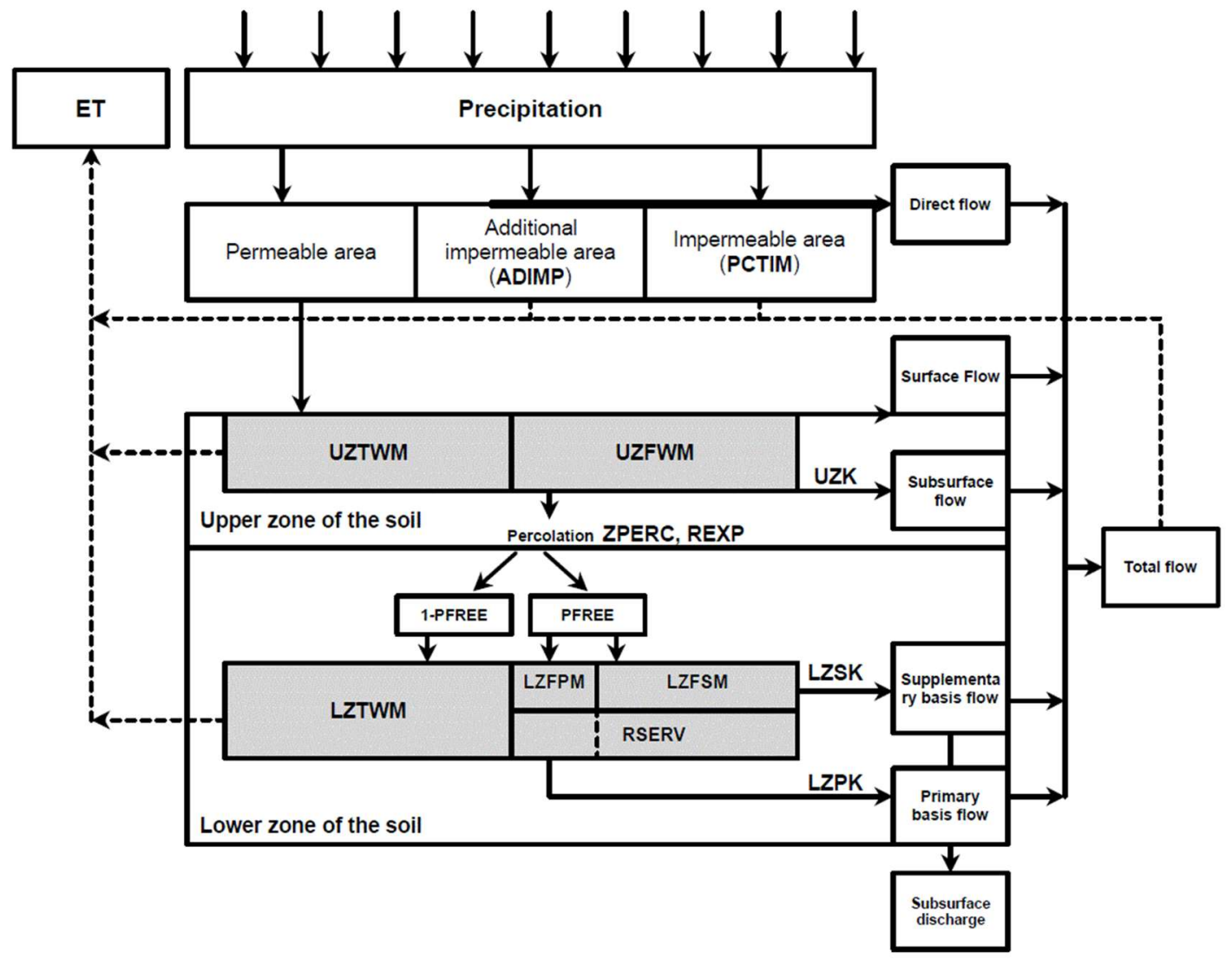

FIGURE 2. Schematic representation of the SAC-SMA model, explaining the optimizable parameters.

Source: Adapted from Van Werkhoven et al. (2009). 
Table 2 shows the SAC-SMA model parameters and Table 3 shows the ranges of parameters proposed by Shin et al. (2013) and used in the GSA procedures of this study.

TABLE 2. Description of the SAC-SMA model parameters (Shin et al., 2013).

\begin{tabular}{|c|c|c|}
\hline Parameter & Unit & Description \\
\hline UZTWM & $\mathrm{mm}$ & Upper zone tension water maximum capacity. \\
\hline UZFWM & $\mathrm{mm}$ & Upper zone free water maximum capacity. \\
\hline LZTWM & $\mathrm{mm}$ & Lower zone tension water maximum capacity. \\
\hline LZFPM & $\mathrm{mm}$ & Lower zone primary free water maximum capacity. \\
\hline LZFSM & $\mathrm{mm}$ & Lower zone supplemental free water maximum capacity. \\
\hline UZK & day $^{-1}$ & Upper zone free water lateral depletion rate. \\
\hline LZPK & day $^{-1}$ & Lower zone primary free water depletion rate. \\
\hline LZSK & day $^{-1}$ & Lower zone supplementary free water depletion rate. \\
\hline PCTIM & $\mathrm{km}^{2} / \mathrm{km}^{2}$ & Fraction of the impervious area. \\
\hline ADIMP & $\mathrm{km}^{2} / \mathrm{km}^{2}$ & Fraction of the additional impervious area. \\
\hline PFREE & $\mathrm{mm} / \mathrm{mm}$ & Direct percolation fraction from upper to lower zone free water storage. \\
\hline ZPERC & none & Maximum percolation rate coefficient. \\
\hline REXP & none & Exponent of the percolation equation. \\
\hline
\end{tabular}

TABLE 3. Variation range of the SAC-SMA model parameters, as proposed by Shin et al. (2013)

\begin{tabular}{cccc}
\hline Parameter & Unit & Lower limit & Upper limit \\
\hline UZTWM & $\mathrm{mm}$ & 1.00 & 150.00 \\
UZFWM & $\mathrm{mm}$ & 1.00 & 150.00 \\
LZTWM & $\mathrm{mm}$ & 1.00 & 500.00 \\
LZFPM & $\mathrm{mm}$ & 1.00 & $1,000.00$ \\
LZFSM & $\mathrm{mm}$ & 1.00 & $1,000.00$ \\
UZK & day $^{-1}$ & 0.10 & 0.50 \\
LZPK & day $^{-1}$ & $10^{-4}$ & 0.25 \\
LZSK & day $^{-1}$ & $10^{-2}$ & 0.25 \\
PCTIM & $\mathrm{km}^{2} \mathrm{~km}^{-2}$ & $10^{-6}$ & 0.10 \\
ADIMP & $\mathrm{km}^{2} \mathrm{~km}^{-2}$ & 0.00 & 0.40 \\
PFREE & $\mathrm{mm} \mathrm{mm}^{-1}$ & 0.00 & 0.60 \\
ZPERC & none & 1.00 & 250.00 \\
REXP & none & 0.00 & 5.00 \\
\hline
\end{tabular}

\section{Morris method}

The numerical procedure described by Campolongo et al. (2007) and Morris (1991), which is deployed in the sensitivity package of the software R, was used to analyze the sensitivity of the SAC-SMA model parameters using the Morris method.

In this method, the SAC-SMA model parameters (Table 2) were considered as a discrete number of evenly spaced values, being quantified the elementary effects or the difference $\left(\mathrm{d}_{\mathrm{i}}\right)$ as a measure of sensitivity. The range of variation of parameters is shown in Table 3 .

The number of simulations ( $\left.\mathrm{N}_{\text {Morris }}\right)$ of the SAC-SMA model required by the Morris method was determined with [eq. (1)].

$$
\mathrm{N}_{\text {Morris }}=\mathrm{r}(\mathrm{k}+1)
$$

Where,

$\mathrm{N}_{\text {Morris }}$ is the number of simulations of the SAC-SMA model;

$r$ is the number of repetitions, and

$\mathrm{k}$ is the number of input parameters of the model.
In this study, $\mathrm{r}$ was equal to $10^{3}$, as recommended by Shin et al. (2013), and k corresponded to 13 since the SACSMA model has 13 input parameters, as shown in Table 2. Thus, the $\mathrm{N}_{\text {Morris }}$ of the SAC-SMA model, for the application of the Morris method, was equal to 14,000 .

For a given set $\mathrm{X}=\left(\mathrm{x}_{1}, \mathrm{x}_{2}, \mathrm{x}_{3}, \ldots, \mathrm{x}_{\mathrm{k}=13}\right)$ of parameters of the SAC-SMA hydrologic model, the elementary effect $d_{i}$ for the i-th parameter was defined by [eq. (2)].

$$
\mathrm{d}_{\mathrm{i}}=\frac{\left[\mathrm{y}\left(\mathrm{x}_{1}, \mathrm{x}_{2}, \ldots, \mathrm{x}_{\mathrm{i}-1}+\Delta, \mathrm{x}_{\mathrm{i}+1}, \ldots, \mathrm{x}_{\mathrm{k}=13}\right)-\mathrm{y}(\mathrm{x})\right]}{\Delta}
$$

Where,

$\Delta$ is a value in $\{1 /(p-1), \ldots, 1-1 /(p-1)\}$,

Where,

$\mathrm{p}$ is the number of levels defined as equal to 10 in this study, and

$y(x)$ is the value of the objective function for the set of $\mathrm{X}$ parameters of the SAC-SMA model.

In this study, the Nash-Sutcliffe coefficient was used as the objective function of the model. 
The value of $d_{i}$ was calculated for a number of $r$ samples equal to $10^{3}$ and the mean $\left(\mu_{\mathrm{i}}\right)$ and standard deviation $\left(\sigma_{\mathrm{i}}\right)$ of these values of elementary effect were obtained by eqs (3) and (4).

$$
\begin{aligned}
& \mu_{\mathrm{i}}=\frac{1}{\mathrm{r}} \sum_{\mathrm{j}=1}^{\mathrm{r}} \mathrm{d}_{\mathrm{i}(\mathrm{j})} \\
& \sigma_{\mathrm{i}}=\sqrt{\frac{1}{\mathrm{r}-1} \sum_{\mathrm{j}=1}^{\mathrm{r}}\left[\mathrm{d}_{\mathrm{i}(\mathrm{j})}\right)^{\left.-\frac{1}{\mathrm{r}} \sum_{\mathrm{j}=1}^{\mathrm{r}} \mathrm{d}_{\mathrm{i}(\mathrm{j})}\right]}}
\end{aligned}
$$

Where,

$\mathrm{d}_{\mathrm{i}(\mathrm{j})}$ is the elementary effect for the input parameter $\mathrm{i}$ using the $\mathrm{j}$-th sampling point, $\mathrm{j}=1,2,3, \ldots, \mathrm{r}$ ( $\mathrm{r}$ is the number of sampling repetitions).

When the model is non-monotonic, some elementary effects $\left(\mathrm{d}_{\mathrm{i}}\right)$ with opposing signals can be canceled. Thus, the proposition of Campolongo et al. (2007) was adopted for calculating $\mu^{*}$ by [eq. (5)].

$$
\mu^{*}=\frac{1}{r} \sum_{j=1}^{r}\left|d_{i(j)}\right|
$$

Mean and standard deviation values obtained by eqs (5) and (4), respectively, indicate the influence of each parameter on the objective function of the hydrologic model.

The value of $\mu^{*}$ estimates the overall effect of each parameter on the model output and the value of $\sigma$ estimates the higher order effects such as non-linearity and interactions between parameters. If $\mu^{*}$ is substantially different from zero, it indicates that the parameter $i$ has an important influence, in general, on the model output. On the other hand, a high value of $\sigma$ implies that the parameter $i$ has a nonlinear effect on the output or there is an interaction between the parameter $i$ and other parameters.

\section{Sobol method}

The numerical procedure proposed by Saltelli (2002), which is deployed in the sensitivity package of the software $\mathrm{R}$, was used to calculate the Sobol index. The Nash-Sutcliffe coefficient was used as the objective function.

The first step to determine the Sobol index was to establish the number of simulations $\left(\mathrm{N}_{\text {Sobol }}\right)$ by means of [eq. (6)].

$$
\mathrm{N}_{\text {sobol }}=\mathrm{M}(\mathrm{k}+2)
$$

Where,

$\mathrm{N}_{\text {Sobol }}$ is the number of simulations of the SAC-SMA model,

$\mathrm{M}$ is the number of repetitions, and

$\mathrm{k}$ is the number of input parameters of the model.

In this study, the $\mathrm{M}$ value was equivalent to $10^{4}$, as recommended by Shin et al. (2013). Because it is the sensitivity analysis of the SAC-SMA model, the value of $\mathrm{k}$ was equal to 13, as shown in Table 2. Thus, the $\mathrm{N}_{\text {Sobol }}$ of the SAC-SMA model, for application in the Sobol method, was equal to 150,000 .

The first-order $\left(\mathrm{S}_{\mathrm{i}}\right)$ and total $\left(\mathrm{S}_{\mathrm{Ti}}\right)$ Sobol indices were quantified. According to Massmann \& Holzmann (2012), the difference between the first-order index and the total index is because it measures the interaction of $i$ with other factors.

Usually, $\mathrm{S}_{\mathrm{Ti}}$ is higher than $\mathrm{S}_{\mathrm{i}}$. According to LopezCruz et al. (2014), if the factor $X_{i}$ is not involved in interactions with other factors, then $\mathrm{S}_{\mathrm{Ti}}=\mathrm{S}_{\mathrm{i}}$, otherwise $\mathrm{S}_{\mathrm{Ti}}>\mathrm{S}_{\mathrm{i}}$.

The difference $\mathrm{S}_{\mathrm{Ti}}-\mathrm{S}_{\mathrm{i}}$ indicates to what extent the factor $\mathrm{X}_{\mathrm{i}}$ is involved in the interactions. If $\mathrm{S}_{\mathrm{Ti}}=0$ is obtained, it implies that the factor $\mathrm{Xi}$ is not influential and can be fixed at any value without affecting the variance of the model output variable. In addition, the sum of all $\mathrm{S}_{\mathrm{i}}$ indices must be equal to the unit in case of additive models and lower than the unit in case of non-additive models. The sum of all $\mathrm{S}_{T i}$ is always higher than the unit value and only equal to the unity in the case of additive models (Lopez-Cruz et al., 2014).

\section{RESULTS AND DISCUSSION}

\section{Morris method}

The results of the global sensitivity analysis (GSA) by the Morris method are shown in Figure 3.

Based on the interpretation of values of mean $\left(\mu^{*}\right)$ and standard deviation $(\sigma)$ of the elementary effects $\left(\mathrm{d}_{\mathrm{i}}\right)$ obtained in the monitoring sections 56696000 (Mário de Carvalho) and 56610000 (Rio Piracicaba), five parameters among the 13 of the SAC-SMA model it was identified by the Morris method, providing higher variations in the output variable, i.e. the daily flow (Figures $3 a$ and $b$ ).

For these two sections, the most important parameter of SAC-SMA was LZTWM (Figure $3 a$ and $b$ ), which represents the maximum water depth retained in the groundwater aquifer and, therefore, unavailable for the base flow.

Figure 4 ( $a$ and $b$ ) shows that the parameter LZTWM, besides having an expressive influence on the flows estimated by the SAC-SMA model, due to the high value of $\mu^{*}$, has high standard deviation value $(\sigma)$, demonstrating that it has interaction with other parameters of the model. 


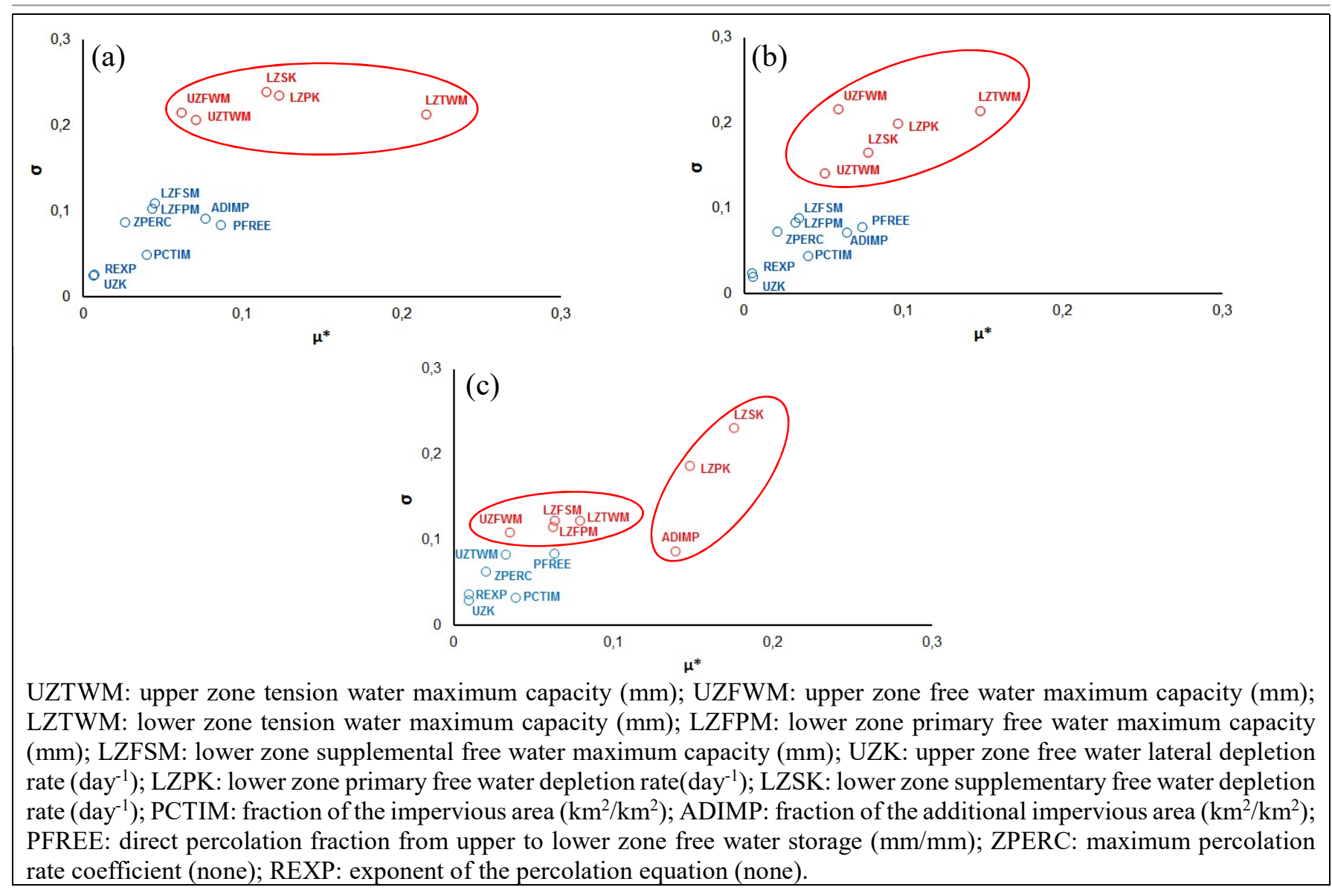

FIGURE 3. Results of the Morris method for the three sections of flow monitoring of the Piracicaba river basin: Mário de Carvalho - 56696000 (a), Rio Piracicaba - 56610000 (b), and Carrapato - 56640000 (c).

The parameters LZPK, LZSK, UZTWM, and UZFWM are also important, but, in general, have little influence in isolation due to the lower values of $\mu^{*}$. However, they must be considered due to the interactions they have with other parameters, explained in the standard deviation value $(\sigma)$.

The parameters LZPK and LZSK represent the base flow depletion. However, UZTWM and UZFWM are parameters related to the storage of water in the upper zone of the soil and interfere with the recharge of the groundwater aquifer and surface and subsurface flows.

Figure 3 ( $a$ and $b$ ) shows that the parameters PFREE, ADIMP, PCTIM, LZFSM, LZFPM, ZPERC, REXP, and UZK presented low sensitivity, with lower values for both the direct effect $\left(\mu^{*}\right)$ and interactions $(\sigma)$. This result suggests that $62 \%$ of the parameters of the SAC-SMA model do not cause significant changes in daily flow estimates in the monitoring sections Mário de Carvalho and Rio Piracicaba. Therefore, they could be fixed by reducing the number of input data and the time required for calibration.

In the monitoring section 56640000 (Carrapato), seven parameters with an expressive influence on the flow values estimated with the SAC-SMA model were identified with the Morris method, as shown in Figure 3c.

In this monitoring section, the parameter that presented the highest sensitivity was the LZSK, which represents the base flow depletion. Figure $3 \mathrm{c}$ shows that this parameter also presents interaction with other parameters due to the high value of $\sigma$.

Moreover, the parameters LZPK and ADIMP also presented a high sensitivity, considering the value of the direct effect $\left(\mu^{*}\right)$. However, the values of $\sigma$ demonstrated that LZPK has an expressive interaction with other parameters, unlike ADIMP.

The parameter LZPK is related to the underground flow depletion. The parameter ADIMP, on the other hand, represents the impermeable area of the basin and the higher its value, the higher the amount of precipitation that will flow superficially.

The parameters LZTWM, LZFSM, LZFPM, and UZFWM have a lower influence on the estimated flows with the SAC-SMA model for the monitoring section Carrapato. However, they should be considered due to their interaction with other factors, explained in the value of $\sigma$ (Figure 3c).

The parameters LZTWM, LZFSM, and LZFPM represent the water storage in the groundwater aquifer and hence have a direct influence on the base flow. On the other hand, UZFWM represents the maximum water depth in the upper zone of the soil that is available for the subsurface flow and groundwater aquifer.

Figure $3 \mathrm{c}$ shows that the parameters PFREE, UZTWM, ZPERC, REXP, PCTIM, and UZK presented a low sensitivity, with low values for both the direct effect $\left(\mu^{*}\right)$ and interactions $(\sigma)$. This result indicates that $46 \%$ of the SACSMA model parameters do not cause significant changes in the daily flow estimates in the monitoring section Carrapato and could be fixed, reducing the number of input data and time required for calibration.

The AGS results indicate that the parameters LZTWM, LZPK, LZSK, UZTWM, and UZFWM related to the surface, subsurface, and base flows of the basin should be determined with higher care due to the great influence they 
have on the flows of the monitoring sections Mário de Carvalho and Rio Piracicaba. For the monitoring section Carrapato, this set of parameters is formed by LZSK, LZPK, ADIMP, LZTWM, LZFSM, LZFPM, and UZFWM.

Results of the Morris method, obtained by Gan et al. (2014) in a basin of the United States, indicated a high sensitivity of the parameters PCTIM, ADIMP, LZTWM, and PFREE, related to surface and base flows. Among the parameters highlighted by these authors, LZTWM presented sensitivity in the three monitoring sections of the flow of the Piracicaba river basin, while PCTIM showed high sensitivity only in the section Carrapato.

When assessing the sensitivity of SAC-SMA with the Morris method in a basin located in the State of Oklahoma, United States, Herman et al. (2013) concluded that the parameters LZFPM, LZFSM, UZK, UZFWM, and ADIMP have a high sensitivity.

Among the parameters highlighted by Herman et al. (2013), only UZFWM had sensitivity for the three sections studied in the Piracicaba river basin. The parameters ADIMP, LZFSM, and LZFPM showed sensitivity only in the monitoring section Carrapato.

Some parameters of the SAC-SMA model, identified as sensitive by Gan et al. (2014) and Herman et al. (2013) in basins of the United States, did not show sensitivity in the
Piracicaba river basin, which may be related to the distinct characteristics of drainage areas. According to Lelis et al. (2012), the divergence of results in the sensitivity analysis is common since the sensitivity of the parameter is especially influenced by soil use and occupation, topography, and other physical and climate factors, which are variable in the drainage areas.

The number of sensitive parameters of the SAC-SMA model identified using the Morris method in the Piracicaba river basin and in other basins suggests that the model does not require calibration of approximately $50 \%$ of the input parameters since changes in their values do not result in significant variations in the output data.

According to Silva (2010), a model is prominent when its inputs cause a variation in the simulated data. Otherwise, when most of the parameters of a model have low sensitivity, as occurred with the SAC-SMA model applied in the Piracicaba river basin, there is an indication that the model is unnecessarily complex.

\section{Sobol method}

Table 4 shows the first-order $\left(\mathrm{S}_{\mathrm{i}}\right)$ and total $\left(\mathrm{S}_{\mathrm{Ti}}\right)$ Sobol indices obtained for the three monitoring sections of the Piracicaba river basin.

TABLE 4. First-order $\left(\mathrm{S}_{\mathrm{i}}\right)$ and total $\left(\mathrm{S}_{\mathrm{Ti}}\right)$ Sobol indices obtained for the three monitoring sections of the Piracicaba river basin.

\begin{tabular}{|c|c|c|c|c|c|c|}
\hline \multirow{3}{*}{ Parameter } & \multicolumn{6}{|c|}{ Fluviometric station } \\
\hline & \multicolumn{2}{|c|}{ Carrapato - 56640000} & \multicolumn{2}{|c|}{ Rio Piracicaba - 56610000} & \multicolumn{2}{|c|}{ Mário de Carvalho - 56696000} \\
\hline & $\mathrm{S}_{\mathrm{i}}$ & $\mathrm{S}_{\mathrm{Ti}}$ & $\mathrm{S}_{\mathrm{i}}$ & $\mathrm{S}_{\mathrm{Ti}}$ & $\mathrm{S}_{\mathrm{i}}$ & $\mathrm{S}_{\mathrm{Ti}}$ \\
\hline UZTWM & 0.001 & 0.004 & 0.065 & 0.081 & 0.043 & 0.057 \\
\hline UZFWM & 0.152 & 0.232 & 0.040 & 0.048 & 0.027 & 0.015 \\
\hline UZK & 0.001 & 0.007 & 0.016 & 0.012 & 0.001 & 0.002 \\
\hline PCTIM & 0.008 & 0.028 & 0.043 & 0.052 & 0.011 & 0.030 \\
\hline ADIMP & 0.118 & 0.172 & 0.002 & 0.012 & 0.024 & 0.040 \\
\hline ZPERC & 0.004 & 0.008 & 0.031 & 0.022 & 0.001 & 0.001 \\
\hline REXP & 0.001 & 0.024 & 0.040 & 0.030 & 0.001 & 0.004 \\
\hline LZTWM & 0.030 & 0.077 & 0.002 & 0.027 & 0.007 & 0.010 \\
\hline LZFSM & 0.026 & 0.222 & 0.013 & 0.044 & 0.014 & 0.067 \\
\hline LZFPM & 0.026 & 0.191 & 0.017 & 0.058 & 0.016 & 0.080 \\
\hline LZSK & 0.078 & 0.226 & 0.233 & 0.304 & 0.196 & 0.276 \\
\hline LZPK & 0.131 & 0.272 & 0.367 & 0.447 & 0.441 & 0.595 \\
\hline PFREE & 0.021 & 0.041 & 0.073 & 0.091 & 0.032 & 0.041 \\
\hline Soma & 0.599 & 1.503 & 0.941 & 1.228 & 0.814 & 1.218 \\
\hline
\end{tabular}

UZTWM: upper zone tension water maximum capacity (mm); UZFWM: upper zone free water maximum capacity (mm); LZTWM: lower zone tension water maximum capacity (mm); LZFPM: lower zone primary free water maximum capacity (mm); LZFSM: lower zone supplemental free water maximum capacity $(\mathrm{mm})$; UZK: upper zone free water lateral depletion rate (day ${ }^{-1}$ ); LZPK: lower zone primary free water depletion rate $\left(\right.$ day $\left.^{-1}\right)$; LZSK: lower zone supplementary free water depletion rate (day $\left.{ }^{-1}\right)$; PCTIM: fraction of the impervious area $\left(\mathrm{km}^{2} / \mathrm{km}^{2}\right)$; ADIMP: fraction of the additional impervious area $\left(\mathrm{km}^{2} / \mathrm{km}^{2}\right)$; PFREE: direct percolation fraction from upper to lower zone free water storage $(\mathrm{mm} / \mathrm{mm})$; ZPERC: maximum percolation rate coefficient (none); REXP: exponent of the percolation equation (none).

Table 4 shows that the parameters LZPK and LZSK presented the highest sensitivity in the drainage areas of the monitoring sections Mário de Carvalho (566960000) and Rio Piracicaba (56610000) as they had the highest values of first$\operatorname{order}\left(\mathrm{S}_{\mathrm{i}}\right)$ and total indices $\left(\mathrm{S}_{\mathrm{Ti}}\right)$.

The parameters LZPK and LZSK corresponded to the depletion rates of the groundwater aquifer and its supplementary recharge, resulting from part of the precipitation that percolated to the lower zone of the soil, respectively. Thus, a high influence of parameters that govern the base flow in the estimated flows for the monitoring sections Mário de Carvalho and Rio Piracicaba is observed.
Table 4 shows that the condition $\mathrm{S}_{\mathrm{Ti}}>\mathrm{S}_{\mathrm{i}}$ is true for the parameters LZPK and LZSK in the sections Mário de Carvalho and Rio Piracicaba, confirming the existence of interaction of them with other parameters.

In the station 56640000 (Carrapato), in addition to LZPK and LZSK, the primary (LZFPM) and supplementary (LZFSM) storages of the groundwater aquifer are also important. In addition, this was the only section that presented sensitive parameters in the upper zone of the soil, which, in this case, were the free water depth in the soil (UZFWM) and additional impermeable area (ADIMP) interfering with the subsurface and surface flow, respectively. 
In this monitoring section, a low difference was observed in the values of the Sobol index of parameters, especially those related to the total effect (Table 4).

All the six parameters of the SAC-SMA model that showed sensitivity to the Carrapato section have $\mathrm{S}_{\mathrm{Ti}}$ values higher than $\mathrm{S}_{\mathrm{i}}$, indicating that they interact with other parameters (Table 4).

With the identification of parameters with higher sensitivity for each monitoring section, the values of the others can remain constant since they do not result in representative modifications in the model output, as described by Song et al. (2015).

The results of the sensitivity analysis with the Sobol method indicate that $85 \%$ of the parameters of the SAC-SMA model do not cause significant changes in the flow estimates in the sections Mário de Carvalho and Piracicaba Rio. These parameters could be fixed by reducing the number of input data and the time required to calibrate the model.

The sensitivity analysis of the station 56640000 (Carrapato) suggested that $54 \%$ of the parameters of the SACSMA model do not cause significant changes in daily flow estimates, which is lower than that obtained for the stations Mário de Carvalho and Rio Piracicaba.

The difference $\mathrm{S}_{T i}-\mathrm{S}_{\mathrm{i}}$ indicates to what extent the parameter is involved in the interactions. Therefore, this difference is higher for the parameters LZFSM, LZFPM, LZPK, and LZSK (Table 4), which correspond to the primary and supplementary underground storage and the respective depletion rates. This result indicates that the parameters that govern the underground flow present a strong interaction with other factors of the SAC-SMA model.

Table 4 shows that in all sections of flow monitoring of the Piracicaba river basin the sum of all the $S_{i}$ indices was lower than 1 and the sum of all the $\mathrm{S}_{\mathrm{Ti}}$ indices was higher than 1 , indicating a non-additive model.

The results of sensitivity analysis by the Sobol method, obtained for the Piracicaba river basin, are in accordance with those of Van Werkhoven et al. (2008), who verified that the parameters LZFSM, LZFPM, LZSK, and LZPK, related to the underground flow, have a high sensitivity in basins located in the United States.

Using the Sobol method to analyze the sensitivity of the SAC-SMA model in the Oregon river basin, located in the United States and Canada, Hameed (2015) concluded that the parameters LZPK, LZTWM, and UZTWM presented a high sensitivity. When comparing the results of this author with those obtained for the Piracicaba river basin, the parameter LZPK, which represents the base flow depletion, was the only one to present sensitivity in the Piracicaba river basin. However, it did not happen for the parameters UZTWM and LZTWM, which correspond to the upper and lower storage of surface tension water, respectively.

Based on the results of global sensitivity analysis of the SAC-SMA model parameters obtained by different methods, among them that of Sobol, Gan et al. (2014) concluded that the parameters UZTWM, PCTIM, ADIMP LZTWM, and PFREE are highly sensitive. In this case, this model was used by the authors in a basin of the western state of Virginia, United States. Among the parameters highlighted by these authors, only that representing the additional impermeable area (ADIMP) had sensitivity for the monitoring section Carrapato.

The difference between the results of the Sobol method obtained for the Piracicaba river basin in relation to those found in the literature is because the sensitivity of the parameter is influenced by soil use and occupation and other physical and climate factors, which are variable in basins, as demonstrated by Lelis et al. (2012).

\section{Joint analysis of the Morris and Sobol methods}

A certain divergence between the results of the Morris and Sobol methods can be observed from the data obtained in this study.

According to Shin et al. (2013), discrepancies may exist in the results obtained with the Morris and Sobol methods, i.e. parameters identified as sensitive by one method may not have the same behavior when considering other method and vice versa. However, the Sobol method is considered more robust than Morris's (Yang, 2011; Zhang et al., 2013) and, therefore, the results of this method are the most indicated.

Cariboni et al. (2007) recommend the Morris method as a preliminary analysis of the use of variance-based GSA methods because it requires shorter computational processing time. Thus, the parameters that do not have sensitivity would be removed from the analysis before using the Sobol method.

In this study, in order to compare the Morris and Sobol methods, the low sensitivity parameters identified by the first method were not removed from the analysis. Thus, the Morris method tends to consider parameters of low sensitivity as having a high sensitivity, but the opposite was not observed.

The Morris method considered the parameters LZTWM, UZTWM, and UZFWM as sensitive for estimating the flows in the monitoring sections Mário de Carvalho and Rio Piracicaba. However, the Sobol method demonstrated that these parameters have no influence on the model output data. For the other parameters, both methods of global sensitivity analysis (GSA) presented similar results.

For the monitoring station Carrapato, both GSA methods had similar results, except for the parameter LZTWM, which is considered important only by the Morris method.

The results obtained for the Piracicaba river basin confirm that the use of the Morris method before the Sobol method is valid since it allows reducing considerably the number of parameters of the SAC-SMA model for the performance of the sensitivity analysis by Sobol. In addition, differences in the results of both GSA methods do not compromise this procedure since the Morris method did not rule out the high sensitivity parameters.

The GSA methods used in this study showed that the SAC-SMA model is unnecessarily complex for application purposes in the Piracicaba river basin since most of the input data do not produce significant variations in its estimated flows.

The global sensitivity analysis indicated that it is possible to set values for most parameters of the SAC-SMA model, simplifying the model and reducing the time required for calibration since the efforts will be concentrated on the estimation of important parameters.

\section{CONCLUSIONS}

Based on the results, we concluded that:

- Most of the SAC-SMA model parameters do not provide significant variations in the output variable (daily flow) when applied in the Piracicaba river basin. 
- The Morris and Sobol methods allow for a possible simplification of the SAC-SMA rain-flow hydrologic model since they enabled the identification of parameters that do not have sensitivity.

- Most of the SAC-SMA model parameters with high sensitivity are the intervenient in the base flow.

- The Morris method should be used as a preliminary analysis of the use of the Sobol method, as it considerably reduces the number of parameters of the SAC-SMA model.

\section{ACKNOWLEDGMENTS}

The authors thank the Minas Gerais Research Foundation (FAPEMIG) and the National Council for Scientific and Technological Development (CNPq) for supporting this research.

\section{REFERENCES}

Andrade MA, Mello CR, Beskow S (2013) Simulação hidrológica em uma bacia hidrográfica representativa dos Latossolos na região Alto Rio Grande, MG. Revista Brasileira de Engenharia Agrícola e Ambiental 17(1):69-76.

Andrews FT, Croke BFW, Jakeman AJ (2011) An open software environment for hydrological model assessment and development. Environmental Modelling \& Software 26(10):1171-1185.

Burnash RJC (1995) The NWS River Forecast System: catchment modeling. In: Singh VP (ed). Computer models of watershed hydrology. Highlands Ranch, Water Resources Publications. p 311-366.

Campolongo F, Cariboni J, Saltelli A (2007) An effective screening design for sensitivity analysis of large models. Environmental Modelling \& Software 22(10):1509-1518.

Cariboni J, Gatelli D, Liska R, Saltelli A (2007) The role of sensitivity analysis in ecological modeling. Ecological Modelling 203(1):167-182.

Devia GK, Ganasri BP, Dwarakish GS (2015) A Review on Hydrological Models. Aquatic Procedia 4:1001-1007.

Gan Y, Duan Q, Gong W, Tong C, Sun Y, Chu W, Ye A, Miao C, Di Z (2014) A comprehensive evaluation of various sensitivity analysis methods: A case study with a hydrological model. Environmental Modelling \& Software 51(1):269-285.

Hameed MA (2015) Evaluating Global Sensitivity Analysis Methods for Hydrologic Modeling over the Columbia River Basin. Dissertation Master of Science in Civil and Environmental Engineering, Portland State University.

Hargreaves GH, Samani ZA (1985) Reference crop evapotranspiration from temperature. Applied Engineering in Agriculture 1(2):96-99.

Herman JD, Kollat JB, Reed PM, Wagener T (2013) Technical Note: Method of Morris effectively reduces the computational demands of global sensitivity analysis for distributed watershed models. Hydrology and Earth System Sciences 17:2893-2903.
Lelis TA, Calijuri ML, Santiago AF, Lima DC, Rocha EO (2012) Análise de sensibilidade e calibração do modelo SWAT aplicado em bacia hidrográfica da região sudeste do Brasil. Revista Brasileira de Ciência do Solo 36(2):623-634.

Lopez-Cruz IL, Rojano-Aguilar A, Salazar-Moreno R, Lopez-Lopez R (2014) Análisis de sensibilidad global del modelo de cultivos sucros aplicado a tomate de cáscara. Revista Fitotecnia Mexicana 37(3):279-288.

Macêdo MNC, Dias HCT, Coelho FMG, Araújo EA, Souza MLH, Silva E (2013) Precipitação pluviométrica e vazão da bacia hidrográfica do Riozinho do Rôla, Amazônia Ocidental. Revista Ambiente \& Água 8(1):206-221.

Massmann C, Holzmann H (2012) Analysis of the behavior of a rainfall-runoff model using three global sensitivity analysis methods evaluated at different temporal scales. Journal of Hydrology 475(1):97-110.

Moreau P, Viaud V, Parnaudeau V, Salmon-Monviola J, Durand P (2013) An approach for global sensitivity analysis of a complex environmental model to spatial inputs and parameters: a case of study an agro-hydrological model.Environmental Modelling \& Software 47(1):74-87.

Morris MD (1991) Factorial sampling plans for preliminary computational experiments. Technometrics 33(2):161-174.

Rakovec O, Hill MC, Clark MP, Weerts AH, Teuling AJ, Uijlenhoet R (2014) Distributed evaluation of local sensitivity analysis (DELSA), with application to hydrologic models. Water Resources Research 50(1):409-426.

Saltelli A (2002) Making best use of model evaluations to compute sensitivity indices. Computer Physics Communications 145(2):280-297.

Sarrazin F, Pianosi F, Wagener T (2016) Global sensitivity of environmental models: Convergence and validation. Environmental Modelling \& Software 79(1):135-152.

Shin M, Guillaume JHA, Croke BFW, Jakeman AJ (2013) Addressing ten questions about conceptual rainfall-runoff models with global sensitivity analyses in R. Journal of Hydrology 503:135-152.

Silva LRS (2010) Análise de incertezas e avaliação dos fatores influentes no desempenho de modelos de simulação de bacias hidrográficas. Tese Doutorado, Brasília, Universidade de Brasília.

Sobol IM (1993) Sensitivity analysis for non-linear mathematical models. Mathematical Modeling and Computational Experiment 1:407-414.

Song X, Zhang J, Zhan C, Xuan Y, Ye M, Xu C (2015) Global sensitivity analysis in hydrological modeling: Review of concepts, methods, theoretical framework, and applications. Journal of Hydrology 523(1):739-757.

Song X, Kong F, Zhan C, Han J, Zhang X (2013) Parameter identification and global sensitivity analysis of Xin'anjiang model using meta-modeling approach. Water Science and Engineering 6(1):1-17. 
Tian W (2013) A review of sensitivity analysis methods in building energy analysis. Renewable and Sustainable Energy Reviews 20(1):411-419.

Van Werkhoven K, Wagener T, Reed P, Tang Y (2008) Characterization of watershed model behavior across a hydroclimatic gradient. Water Resources Research 44(1):116.

Van Werkhoven K, Wagener T, Reed P, Tang Y (2009) Sensitivity-guided reduction of parametric dimensionality for multi-objective calibration of watershed models. Advances in Water Resources 32(8):1154-1169.
Yang J (2011) Convergence and uncertainty analyses in Monte-Carlo based sensitivity analysis. Environmental Modelling \& Software 26(4):444-457.

Zhan CS, Song XM, Xia J, Tong C (2013) An efficient integrated approach for global sensitivity analysis of hydrological model parameters. Environmental Modelling \& Software 41(1):39-52.

Zhang C, Chu J, Fu G (2013) Sobol's sensitivity analysis for a distributed hydrological model of Yichun River Basin, China. Journal of Hydrology 480:58-68. 